\title{
Acesso aos serviços de saúde por mães cegas: dos enfrentamentos aos ensinamentos
}

Access to health services by blind mothers: from coping to learning

Acceso a los servicios de salud por madres ciegas: del enfrentamiento a la enseñanza

Camilla Pontes Bezerra ${ }^{1}$ iD https://orcid.org/0000-0002-9564-5623

Ana Izabel Oliveira Nicolau² id https://orcid.org/0000-0002-6584-0575 Georgia Patrícia Pontes Bezerra ${ }^{3}$ io https://orcid.org/0000-0003-1994-6499 Márcia Maria Tavares Machado ${ }^{4}$ io https://orcid.org/0000-0002-0149-5792 Lorita Marlena Freitag Pagliuca ${ }^{5}$ io https://orcid.org/0000-0001-9110-8102

Como citar:

Bezerra CP, Nicolau Al, Bezerra GP, Machado MM, Pagliuca LM. Acesso aos serviços de saúde por mães cegas: dos enfrentamentos aos ensinamentos. Acta Paul Enferm. 2020;33:eAPE20190197.

DOI http://dx.doi.org/10.37689/actaape/2020A001975

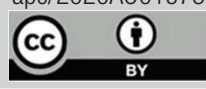

Educação de pessoas com deficiência visual; Saúde da mulher; Acesso aos serviços de saúde; Relações mãe-filho

Keywords

Education of visually disabled; Women's health; Health services accessibility; Mother-child relations

Descriptores

Educación de personas con discapacidad visual; Salud de la mujer; Accesibilidad a los servicios de salud; Relaciones madre-hijo

Submetido 26 de Julho de 2019

Aceito

16 de Março de 2020

Autor correspondente

Camilla Pontes Bezerra

Email: camilla.pontes@unifesp.br

\section{Resumo}

Objetivo: Conhecer na percepção e vivências de mães cegas como ocorre 0 acesso aos serviços de atenção básica de saúde em Fortaleza, Ceará.

Métodos: Trata-se de um estudo de abordagem qualitativa realizado na cidade de Fortaleza-Ceará, com vinte mães cegas que tinham filhos de zero a dez anos de idade. A coleta de dados ocorreu no primeiro semestre de 2017 por meio de entrevista semiestruturada. Utilizou-se o interacionismo simbólico como referencial teórico e a análise de conteúdo temática, segundo Bardin, como método de análise.

Resultados: A análise dos dados permitiu compreender como se dá a experiência de acessibilidade das mães cegas nas unidades de saúde, sendo que as categorias apreendidas no estudo foram: acessibilidade das mães cegas às unidades de saúde e 0 cuidado prestado às crianças nas unidades de saúde. A falta de habilidade dos profissionais para atender as pessoas com deficiência foi evidenciada, apontando um sério problema que necessita ser minimizado, com a preparação destes profissionais que atendem na rede pública de saúde, desde a sua formação acadêmica.

Conclusão: Considera-se, ainda, que muito necessita ser transformado nos serviços de saúde em busca da acessibilidade da pessoa com deficiência. Evidencia-se a necessidade de cumprir os padrões legais em busca do acesso facilitado a essas mães cegas e seus filhos aos serviços públicos.

\section{Abstract}

Objective: To know according to the perception and experiences of blind mothers how access to primary health care services occurs in the city of Fortaleza, Ceará.

Methods: This is a qualitative study conducted in the city of Fortaleza, Ceará, with twenty blind mothers who had children from zero to ten years old. Data collection took place in the first half of 2017 through semistructured interviews. Symbolic Interactionism was used as a theoretical framework and thematic content analysis, according to Bardin, as a method of analysis.

Results: Data analysis allowed us to understand how the experience of accessibility of blind mothers in health units takes place. The categories learned in the study were: "Accessibility of blind mothers to health units" and "Children care in health units". The professionals' lack of ability to care for people with disabilities was evidenced, pointing out a serious problem that needs to be minimized, with the preparation of these professionals from public health network since their academic training. 
Conclusion: It is also considered that much needs to be transformed in health services in search of accessibility for people with disabilities. The need to comply with legal standards in search of easier access for these blind mothers and their children to public services is evident.

\section{Resumen}

Objetivo: Conocer cómo es el acceso a los servicios de atención básica en salud según la percepción y vivencias de madres ciegas, en Fortaleza, estado de Ceará. Métodos: Se trata de un estudio de enfoque cualitativo realizado en la ciudad de Fortaleza, estado de Ceará, con 20 madres ciegas que tenían hijos de 0 a 10 años de edad. La recolección de datos se llevó a cabo el primer semestre de 2017 mediante entrevista semiestructurada. Se utilizó el interaccionismo simbólico como referencia teórica y el análisis de contenido temático, según Bardin, como método de análisis.

Resultados: El análisis de los datos permitió comprender cómo es la experiencia de accesibilidad de las madres ciegas en las unidades de salud, y las categorías captadas en el estudio fueron: la accesibilidad de las madres ciegas en las unidades de salud y los cuidados que reciben los niños en las unidades de salud. La falta de habilidad de los profesionales para atender a personas con discapacidad es evidente, lo que deja ver un serio problema que debe ser mitigado con la preparación de estos profesionales que atienden en el sistema de salud pública, desde su formación académica.

Conclusión: Se considera que aún hay mucho para cambiar en los servicios de salud para lograr la accesibilidad de la persona con discapacidad. Queda en evidencia la necesidad de cumplir los estándares legales para facilitar el acceso de estas madres ciegas y sus hijos a los servicios públicos.

\section{Introdução}

A acessibilidade como princípio do Sistema Único de Saúde (SUS) garante à população a oferta de serviços, que devem estar qualificados para atender e resolver os principais problemas aos que os demandam.

A acessibilidade é um conceito estreitamente ligado aos direitos das pessoas com deficiência. Estes indivíduos recebem esta denominação em virtude de apresentarem uma perda parcial ou total das funçôes ou estruturas do corpo, incluindo as psicológicas, o que lhes resulta o enfrentamento de dificuldades específicas e susceptíveis na limitação de atividades ou restringir a participação na vida social, econômica e cultural. ${ }^{(1)}$

Conforme a Associaçáo Brasileira de Normas Técnicas (ABNT) são acessíveis o espaço, a edificação, o mobiliário ou elemento que possa ser alcançado, visitado e utilizado por qualquer pessoa, inclusive aquelas portadoras de uma deficiência qualquer. ${ }^{(2)}$ Essa norma utiliza o conceito "acessível" tanto para a acessibilidade física como para a comunicação e sinalização e define acessibilidade como a possibilidade e condição de alcance para utilização, com segurança e autonomia, de edificaçóes, espaço, mobiliário e equipamento urbano. ${ }^{(2)}$

O princípio da acessibilidade transcende a compreensão da necessidade da existência de um serviço de saúde próximo à sua realidade vivenciada pela comunidade. Evidencia-se o fato de que a Estratégia Saúde da Família (ESF) busca oferecer, na sua dinâmica assistencial, maior acesso e resolubilidade para os usuários. ${ }^{(3)}$
Com amparo na política de saúde vigente no Brasil, verifica-se a necessidade de que seja propiciada às pessoas com deficiência e seus familiares uma atenção integral, possibilitando sua inclusão à comunidade e melhorando sua qualidade de vida, segundo as suas possibilidades. ${ }^{(4)}$

De acordo com os dados do IBGE $^{(5)}$ estima-se que existam cerca de 140 mil pessoas cegas, integrantes na sociedade, sem contudo se ter informaçôes mais detalhadas sobre a acessibilidade das mesmas aos serviços de atenção básica. ${ }^{(6)}$

A mulher cega, como parte do desenvolvimento humano normal, pode gerar filhos em algum momento de sua vida, sendo capaz de cuidar e acompanhar o seu desenvolvimento, mesmo que para isso, necessite de suporte familiar e da equipe de saúde.

Estudos realizados em Fortaleza constataram a complexidade de situaçóes vivenciadas pelos pais cegos quando amamentam, alimentam, banham e administram medicamentos. Os pais com deficiência visual desenvolvem estratégias criativas no cuidado com os filhos com o uso do olfato e do tato, o apoio de familiares e vizinhos. Reforçam que os profissionais de saúde, especialmente os enfermeiros, devem estar mais próximos a essas pessoas e produzir conhecimento para esse grupo tão pouco contemplado em nossa sociedade. ${ }^{(7,8)}$

Baseados nestes estudos que vem sendo desenvolvidos por pesquisadores no Ceará, com pessoas cegas, alguns questionamentos surgiram para aprofundamento dessa temática, quais sejam: Como as mães cegas estão sendo acolhidas no serviço de saúde pública? Quais as facilidades e dificuldades para 
obterem acesso fácil aos serviços de atenção básica em Fortaleza?

Dessa forma, como contribuição ao debate mais aprofundado junto à sociedade acadêmica e à comunidade em geral sobre esse tema, objetivou-se com esta pesquisa conhecer o acesso aos serviços de saúde na percepção e vivências de mães cegas, nos serviços de atenção básica de saúde em Fortaleza, Ceará.

\section{Métodos}

Trata-se de um estudo qualitativo realizado em Fortaleza-CE, no período de março a julho de 2017, com mães cegas e que possuíam filhos na faixa etária de 0 a 10 anos de idade (abrangendo primeira, segunda e terceira infâncias), fases em que as crianças estão mais susceptíveis a doenças ou a agravos à saúde e apresentam mais necessidades de cuidados e busca por serviços de saúde.

A população foi constituída por vinte mães, obtida intencionalmente, recorrendo-se à técnica de bola de neve, na qual um sujeito indica um conhecido, com as características definidas para a busca na comunidade. ${ }^{(9)}$

Para a definição do número de participantes adotamos a técnica de saturaçáo dos dados, que ocorre quando as informaçôes analisadas se tornam repetitivas, ou seja, náo aparecem novas ideias ou conceitos no decorrer das entrevistas realizadas. ${ }^{(9)}$

Utilizou-se, também, a identificação de mães cegas cadastradas no sistema municipal de saúde de Fortaleza-CE. Houve dificuldades, entretanto, para encontrar as mães cegas, na rede pública, pois não há um cadastro específico no sistema de saúde, dos usuários com algum tipo deficiência. Esse registro, também, não classifica os diferentes tipos de deficiências, tais como física, visual, auditiva e mental. Os contatos foram obtidos com base na indicação de deficientes visuais, bem assim convocando pelas emissoras de rádios e de TV de Fortaleza, que relatavam os objetivos da pesquisa e solicitavam, a quem conhecesse uma mãe cega, que ligasse para o telefone de apoio da pesquisa.

As mães cegas entrevistadas tinham entre $21 \mathrm{e}$ 42 anos de idade; quatro possuíam o ensino fun- damental incompleto, quatro o ensino fundamental completo, oito o ensino médio completo, duas tinham pós-graduação e duas não responderam à pergunta; 16 delas viviam em uniáo estável e 4 eram casadas, todas tinham moradia própria, com condições sanitárias adequadas e possuíam renda familiar acima de um salário mínimo; 17 haviam tido os filhos por parto tipo cesariana e 03 vivenciaram partos normais.

$\mathrm{Na}$ primeira etapa da coleta de dados, um formulário de múltipla escolha foi lido e preenchido pela entrevistadora, de acordo com as respostas dadas pela mãe cega entrevistada. O formulário privilegiava aspectos da identificação (idade, escolaridade, tipo de deficiência visual, situação conjugal, ocupaçáo, tipo de moradia, condiçóes sanitárias da moradia, renda familiar, idade do filho e tipo de parto).

No segundo momento, a entrevistadora realizou uma entrevista individual com as mães cegas, utilizando um roteiro com perguntas semiestruturadas em relação ao acesso aos serviços de saúde, tendo como questão norteadora: Como a senhora utiliza os serviços de saúde quando precisa de uma consulta médica ou de outro profissional de saúde?. As mesmas foram realizadas nos domicílios das mães, utilizando gravação, permitida previamente, para obter maior fidedignidade dos relatos verbalizados. O tempo de duração de cada entrevista variou entre 55 e 122 minutos.

Para a compreensão dos dados obtidos nas entrevistas, foi utilizado o interacionismo simbólico como referencial teórico. O interacionismo simbólico se baseia em três premissas: o ser humano age em relação às coisas, com base no significado que têm para ele; esses significados são resultantes da interpretação social e individual estabelecida com outras pessoas; e tais significados são modificados a partir de processo interpretativo utilizado pela pessoa ao lidar com situaçóes vivenciadas e objetos encontrados. ${ }^{(10)} \mathrm{Na}$ perspectiva do interacionismo simbólico e no escopo da pesquisa, o significado emerge a partir do processo de interação entre mães cegas e profissionais de saúde dos serviços procurados por elas no momento de prestação de cuidados aos seus filhos. 
Foram realizadas transcriçóes das falas e leituras repetidas das narrativas coletadas. Estas foram submetidas à técnica de análise de conteúdo temática. ${ }^{(11)}$ Após a análise aprofundada das falas, foram identificadas duas categorias: $1 \mathrm{O}$ acesso das mães cegas às unidades de saúde; e $2 \mathrm{O}$ cuidado prestado às crianças nas unidades de saúde.

O projeto foi aprovado pelo Comitê de Ética em Pesquisa da Universidade Federal do Ceará. As participantes da pesquisa assinaram o Termo de Consentimento Informado, após leitura feita pela entrevistadora e com a presença de uma testemunha, de confiança da mãe cega.

Ressalta-se que este estudo seguiu todos os critérios estabelecidos no instrumento Consolidated criteria for reporting qualitative research (COREQ) enquanto ferramenta de apoio em relação ao padrão para relatórios de estudos qualitativos.

\section{Resultados}

A análise dos dados permitiu compreender como se dá a experiência de acessibilidade das mães cegas nas unidades de saúde, sendo que as categorias apreendidas no estudo foram: acessibilidade das mães cegas às unidades de saúde e o cuidado prestado às crianças nas unidades de saúde, as quais serão descritas a seguir, ilustradas com dados extraídos dos discursos das mães.

\section{Acessibilidade das mães cegas às unidades de saúde}

As mães relataram que começaram o pré-natal assim que descobriram a gravidez. Algumas delas contaram que, na unidade básica de saúde, os profissionais as encaminhavam desde cedo a uma instituição de nível secundário ou terciário, pois, pelo fato de serem deficientes visuais, eram consideradas como de "risco" para um nascimento prematuro ou a possibilidade de alguma intercorrência. Aquelas que tinham a oportunidade de pagar por um plano privado mencionavam a diferença de atendimento, especialmente, no número mais acentuado de exames complementares que os médicos solicitavam, conforme descrevem:
"Procurei logo fazer o pré-natal, cuidar tudo direitinho, pra mim foi do mesmo jeito. Sendo que da outra filha eu fui mais assistida porque nas ulttimas consultas eu fiz dois pré-natal, porque a outra filha eu tive em Caucaia (municipio situado na região metropolitana da cidade de Fortaleza) que foi onde eu fiz a minha laqueadura" (EG).

“...aqui no posto, quando eu fui, eles disseram que não iam poder ficar comigo... Foi uma doutora que disse que não ia ficar comigo porque eu era desse jeito (cega), eu era muito estreitinha, era deficiente e tudo, então ela achava que eu não teria condiçóes de ter um filho e se tivesse o menino ia nascer de seis meses" (E1).

"Olha assim, na época da minha última gestação eu tinha um plano de saúde, aíplano de saúde você sabe como é, é um exame atrás do outro" (E4).

As mães entrevistadas relataram, ainda, que na maioria das vezes, a consulta pré-natal se limitava a exames físicos rotineiros, como a medição da circunferência abdominal, avaliação do peso e ausculta do bebê, sem uma orientação sobre o cuidado materno e infantil:

"Ai a médica colocava (fita métrica) e media a barriga e ouvia o coraçáo do nenê e ver se estava tudo bem com ele" (E12).

"Só era o peso, verificar a pressão e medir a barriga e pronto, nada mais" (E8).

É importante observar que algumas mães revelaram não terem tido acesso à educação em saúde, como orientaçóes sobre amamentação e cuidados com o recém-nascido. Também não foram descritos momentos de diálogos entre as mães e profissionais de saúde sobre as condições psicossociais da mãe, evidenciando a falta de um cuidado holístico e humanizado por parte dos profissionais de saúde, conforme se pôde constatar:

"Normal. Consulta de pré-natal mesmo. Chegava lá fazia a consulta de pré-natal e ia embora. Não 
falava, não conversava nada sobre amamentação $e$ cuidados com o bebê não" (E16).

“...Na gravidez não tive explicação não... Não falava sobre amamentação náo. Falava só a respeito de repouso, pra mim ter repouso, não fazer muito arte, essas coisas assim, mas cuidado com o bebê não" (E7).

As mães entrevistadas descreveram, também, os seus momentos ao chegar às maternidades, apontando a falta de esclarecimento sobre o trabalho de parto e a decisão apontada pelos médicos em optar pela cesárea, como forma de "aliviar o sofrimento", conforme descrevem:

"Ai eu fui, passei a noite todinha, não tinha anestesista lá na hora. Cheguei no domingo, não tinha anestesista ai eu esperei, quando foi seis horas da manhã, a médica fez o toque... Ai ela disse, "rapaz" você poderia esperar, mas é mais sofrimento. $E$ melhor ter logo porque é tanto sofrimento pra você como pro bebê. Tinha tudo normal, só que não rompia. Ai ela disse, eu vou logo fazer. Chamou logo o anestesista pra ele chegar cedo, antes da hora, ai fez. Só foram quinze minutos, foi rápida demais" (E20).

"Na hora a gente fica insegura, mas logo depois a gente passa a ter uma segurança maior porque assim, quando você tá do lado do profissional que está te tratando bem, a gente passa a confiar" (E2).

As mães relataram, também, que não foi permitida a entrada de acompanhantes na sala de parto, com a descrição sobre seus sentimentos de insegurança e de medo, por estarem sozinhas. A falta de sensibilidade de alguns profissionais na sala de parto é apontada como elemento importante para ampliar a sensação de solidáo e angústia, vivenciada por essas mulheres cegas, durante o parto, conforme relatam:

"Aí eu fiquei só numa sala, sozinha, não tinha nem outra mulher pra gemer comigo... Nấo teve acompanhante. Só teve acompanhante a noite quando eu tive a bebê já... Ai eu achei triste, muito frio, você se sente abandonada, chega a pessoa só pra lhe dar carão, porque você começa a gemer devido ao nervosismo, não é nem por causa da dor. É o nervosismo que dá, você vê todo mundo tendo nenê e você náo. Porque ficou só eu, porque eu comecei a sofrer..." (E18).

"Não, ninguém entrou, só deixou lá fora (o marido) e voltou pra casa e pronto" (E3).

\section{0 cuidado prestado às crianças nas unidades de saúde}

A escolha do atendimento baseia-se na confiança e na empatia entre profissional de saúde e usuário. As mães consideram que a consulta aos seus filhos não é satisfatória, pois não houve interesse dos profissionais em realizar uma consulta mais aprofundada, em que fosse utilizado um tempo maior, suficiente para realização de um exame clínico adequado. Com atenção a estas falas, reflete-se sobre a qualidade do atendimento prestado à criança, filha de mães cegas.

"No começo, na primeira consulta dele eu não gostei muito não. Só o que ele fez foi isso, perguntou se a criança estava comendo bem e tudo, mas não examinou a criança de jeito nenhum" (E5).

"Ah, eu acho assim, que deixa muito a desejar.. É bastante fechada. Eles náo tem muito tempo pra criança, não examina, porque realmente não tem nem espaço, o espaço é muito pequeno, então não tem nem como acompanhar direito lá" (E17).

As mães também reivindicam o direito de acompanhar seus filhos e exigem serem reconhecidas como competentes para cuidarem dos mesmos e os acompanharem à unidade de saúde:

"Bastante difícil. Porque eles nem entendem na maioria das vezes que a gente pode ir naquele posto de saude só com o filho da gente, eles acham que a gente tem a obrigação de levar uma pessoa que enxerga" (E2).

“...logo da portaria o pessoal náo queria que eu entrasse com o menino. Eu tinha ido com uma pes- 
soa que eu náo conheço direito. O pessoal queria que eu deixasse ela entrar com o menino porque eu era cega. ... briguei que oflho era meu, quem tinha que entrar era eu, eles achavam que por eu ser cega não podia acompanhar..." (E9).

Porém, as usuárias sentem-se bem atendidas, principalmente quando têm sua autonomia respeitada e participam do seu processo de cura. Nas falas seguintes, percebe-se o quanto o vínculo formado entre as mães cegas e o serviço permitiu um atendimento de saúde eficaz:

“...Quando eu vou dar a vacina dele... a enfermeira que estava dando a vacina dele ela me explicou como é que podia fazer. Aí disse o que eu podia fazer com ele se por acaso ele ficasse muito enjoado com a vacina da coxa, disse que eu podia colocar um pouquinho de gelo pra não doer muito. Então ela foi bem explicativa mesmo eu gostei” (E11).

"Tratam bem. As enfermeiras fazem tudo pra não separar o bebê de mim, ter aquele cuidado de ir junto comigo porque o maior medo que eu tenho é de ter que separar uma delas de mim..." (E13).

\section{Discussão}

O acesso facilitado a uma gestante e puérpera é compreendido como elemento essencial para o diagnóstico precoce, além do estabelecimento de uma relação dialógica entre os profissionais de saúde das unidades e a clientela. ${ }^{(12)}$ Em se tratando de uma mulher com deficiência, além da abordagem comunicacional, torna-se essencial ter uma estrutura física que propicie uma entrada facilitada à unidade de saúde, com rampas e recepção apropriada. ${ }^{(13)}$

A falta de habilidade dos profissionais para atender as pessoas com deficiência foi evidenciada, apontando um sério problema que necessita ser minimizado, com a preparação destes profissionais que atendem na rede pública de saúde, desde a sua formação acadêmica.

Percebe-se que há uma preferência dos profissionais por exames mais sofisticados, levando a uma referência precoce aos serviços, onde a capacidade tecnológica é maior e que o acesso a esses procedimentos se torna mais fácil nos planos privados de saúde. A utilização das laqueaduras demonstra a falha no planejamento reprodutivo, que deveria ser agregado ao pré-natal, oferecendo à mulher autonomia sobre o seu corpo, sem se submeter a procedimentos cirúrgicos. ${ }^{(14)}$

Segundo os relatos, o pré-natal se limitava a exames físicos rotineiros. Estes procedimentos permitem uma detecção precoce de fatores de risco na gravidez, como hipertensão e diabetes, que podem levar a uma complicação, causas frequentes de morte materna e perinatal durante o parto. Geralmente nas consultas de pré-natal são realizados procedimentos de acompanhamento do crescimento fetal, com suporte no comprimento do abdome gravídico. São verificados os valores da pressão arterial e o peso, procedimentos de acompanhamento da saúde da grávida para saber se há condiçóes de risco. ${ }^{(15)}$

Porém, não havia qualquer orientação sobre o cuidado materno e infantil, o que conduz à reflexão quanto à qualidade do pré-natal, em que deve ser abordada a saúde física da gestante e do feto, mas hão de ser integradas, também, ações referentes a aspectos da saúde psicossocial, haja vista que essa mulher necessita deste suporte, tanto da comunidade e da família, quanto dos profissionais, a fim de obter sucesso no parto e nos cuidados à criança. ${ }^{(16)}$

A deficiência de acesso à educação em saúde, inclusive sobre orientaçôes essenciais relacionadas à amamentação e cuidados com o recém-nascido foi evidenciada. Apesar de o aleitamento materno ser uma prática natural, não é totalmente instintiva, sendo necessário suporte, especialmente em se tratando de uma mãe com deficiência visual. ${ }^{(17)}$

As práticas de Educação em Saúde devem ser voltadas para as especificidades do cliente, visando a uma apreensão adequada destes conhecimentos para torná-los práticas cotidianas. No caso dos cegos, deve-se reforçar na comunicação necessária para a orientação dos sentidos remanescentes, como o olfato, o tato e a audição, ultrapassando assim o que é tradicional, uma vez que a principal tecnologia utilizada para Educação em Saúde está em materiais visuais. 
No universo pesquisado a fragilidade do acolhimento das máes no momento do ingresso à maternidade e a falta de esclarecimento sobre o trabalho de parto estiveram presentes. $\mathrm{O}$ nascimento de uma criança é percorrido por uma série de emoçóes, sentimentos de incertezas, que historicamente reforça uma condição de medo e ansiedade às mulheres durante todo o período da gestação. No Brasil aconteceu uma mudança das práticas naturais do nascimento de uma criança, com alta prevalência de partos cesarianos. ${ }^{(18)}$

Autores descrevem que há maior aceitação pelo parto natural, quando são fornecidas orientaçôes sobre os procedimentos do parto, a capacitação técnica dos profissionais envolvidos de utilizar técnicas analgésicas não medicamentosas, bem como o envolvimento do acompanhante durante todo o trabalho de parto. O enfermeiro é o profissional que mais incentiva a realização deste tipo de parto. ${ }^{(19)}$ Em alguns casos, entretanto, é necessária a intervenção cirúrgica, em que se deve priorizar a segurança da vida do binômio mãe-filho. ${ }^{(20)}$

Outro fator agravante foi o fato de não ter sido permitida a entrada de acompanhantes na sala de parto. É assegurado o direito à presença do acompanhante no momento do parto, devendo haver um ajuste do espaço físico e da abordagem da equipe para receber de forma adequada um novo integrante da sala de parto. $\mathrm{O}$ acompanhamento de um familiar, do companheiro ou de um amigo durante o parto aumenta a confiança da mulher em ser mãe, diminui a utilização de medicamentos para analgesia, reforça a autonomia da mulher nas decisóes sobre seu corpo e aumenta o tempo de amamentação. Em algum momento os profissionais podem estar aptos a participar da rede de apoio destas mulheres, oferecendo-lhes confiança e conforto emocional. ${ }^{(21,22)}$

Sabe-se que é importante integrar uma equipe multiprofissional para prestar o cuidado adequado à criança, com consultas que avaliem o desenvolvimento e promovam açóes de prevenção de doenças. Outro fator importante é a participação dos pais na consulta, pois estes são a principal fonte de informação sobre a criança, referindo histórico familiar, situação da comunidade na qual a criança está inserida, rede de apoio necessária para o desenvolvi- mento dela. $\mathrm{O}$ atendimento deve ser personalizado e holístico, devendo-se utilizar formulários apenas para orientar a consulta, sendo estas adaptadas a tal situação. As informações transmitidas aos pais deve ser reforçada com algum material informativo para captação efetiva desta. ${ }^{(23)}$

No caso dos pais cegos, essas informações devem estar disponíveis em material tátil e auditivo, podendo até mesmo estar dispostas em meio eletrônico para os cegos, com acesso à internet. $\mathrm{O}$ uso de tecnologia deve auxiliar o profissional de saúde na transmissão de conhecimentos relacionados à Educação em Saúde para a clientela cega, permitindo a acessibilidade desta informação. ${ }^{(24)}$

O vínculo formado entre profissional de saúde e usuário promove um atendimento adequado, concordando com os princípios do SUS. Para a efetividade dos serviços, é necessário ter uma equipe comprometida com o trabalho, em número suficiente e que escute as opinióes do usuário, modificando o serviço de acordo com a necessidade da clientela. Assim, forma-se um serviço em que existe uma co-participação entre usuários e profissionais, a fim de tornar o acesso aos serviços de saúde integral e efetivo.

Com relação as crianças, as mães se sentem responsáveis pela saúde de seus filhos e como suas cuidadoras. Portanto, é importante respeitar seu direito de acompanhá-los nos atendimentos da unidade de saúde. Independentemente de sua deficiência, a mãe cega é capaz de cuidar de seus filhos e, como outras mulheres, costuma ser a cuidadora da família, sendo, assim, responsável pelo acompanhamento da criança aos serviços de saúde.

As mães conseguem adaptar-se aos fatores estressores no cuidado com os filhos, algumas com auxílio de terceiros, e outras com determinação e criatividade, ou seja, elas pensam, reformulam ideias, recriam estratégias e métodos para implementar adequadamente todos os cuidados de forma autônoma.

\section{Conclusão}

Acredita-se que este trabalho possa contribuir para o conhecimento de como se dá a vivência da materni- 
dade no contexto da deficiência visual, considerando que em meio aos resultados obtidos com a teoria do interacionismo simbólico tenha se propiciado aos profissionais de saúde identificar e reconhecer os elementos que a compóem e assim poder clarificá-los à paciente cega. A teoria do interacionismo simbólico mostrou importância durante a coleta e análise dos dados, pois as fases da teoria foram bem interligadas com as ações das mães cegas, possibilitando perceber o desejo que elas têm de se superar diante da sociedade no cuidado com seu filho. Observando este aspecto, perguntou-se ao longo do contato com os dados e sua análise, sobre os reflexos da deficiência visual materna nos filhos, não apenas no que tange ao comportamento infantil, desempenho de aprendizagem e cuidados recebidos. Considera-se que há um grande número de trabalhos que apresentem a criança apenas na perspectiva dos aspectos citados (comportamento, aprendizagem e formas de cuidados), havendo uma lacuna de trabalhos que enveredem pelas percepçóes e sentimentos filiais com relação à genitora cega. Considera-se como limitação desse estudo o fato de não ter sido abordada também a percepção do filho de mãe cega em relação aos cuidados prestados. Tendo em vista o que este estudo propiciou conhecer sobre as especificidades das mães, mulheres cegas, pode-se contar com outros recursos para a melhor adequação dos serviços de saúde para o atendimento do usuário, o que não necessariamente requer a formação de novos serviços, mas a inclusão de novos saberes, olhares e posturas frente àquela que busca por atendimento. Como meio de adequar os atendimentos de saúde à essas mães, sugere-se a capacitação dos profissionais de saúde e a formação de grupos informativos, em que se abordem os cuidados referentes aos filhos, bem como se dê abertura para que as mães possam expor suas concepçóes e experiências. Tal iniciativa pode constituir-se como um recurso relativamente simples de ser implementado. Outra sugestão de atuação junto a mães cegas trata-se de não apenas o suporte advir dos serviços formais, mas também poder contar com o suporte informal da família, assim como poder contar com outras mães que já estejam mais fortalecidas emocionalmente para que sirvam de multiplicadoras entre seus pares. Finalmente, é importante considerar a contribuição desse trabalho para a inserção do profissional de saúde no contexto do tratamento dessas mães. Ao profissional de saúde requer maior habilidade em estabelecer um contato mais humanizado do cuidado, com a possibilidade de realizar uma abordagem da mãe cega de modo a ter uma escuta privilegiada para as demanda destas mulheres, desprovidas do reconhecimento de suas necessidades. Esta postura deve estar aliada à proposta de formação de equipe multiprofissional para a atuação em saúde. Os saberes de cada área devem ser construtos de propostas de cuidado e atenção, sem perder suas especificidades na assistência, mas aptos a um olhar integrativo das necessidades do usuário do serviço. As mães relataram um desejo de superação diante da sociedade e da família quando decidiram ter seus filhos e este desejo foi alcançado, pois mesmo com as suas limitaçôes demonstraram ser capazes de cuidar de seus filhos.

\section{Colaborações}

Bezerra CP e Machado MMT participaram da concepção e projeto, análise e interpretação dos dados. Nicolau AIO, Bezerra GPP e Pagliuca LMF participaram da redação do artigo e revisão crítica relevante do conteúdo intelectual; todos os autores participaram da aprovação final da versão a ser publicada.

\section{Referências}

1. Brasil. Decreto-Lei No 5296, de 02 de dezembro 2004. Regulamenta as Leis $\mathrm{N}^{\circ}$. 10.048, de 8 de novembro de 2000, que dá prioridade de atendimento às pessoas que especifica, e 10.098, de 19 de dezembro de 2000, que estabelece normas gerais e critérios básicos para a promoção da acessibilidade [Internet]. [citado 2017 Set 10]. Disponível em: http://www.acessobrasil.org.br/index.php?itemid=43.

2. Associação Brasileira de Normas Técnicas - ABNT. NBR 9050. Acessibilidade a edificações, espaço, mobiliário e equipamentos urbanos. In: Coordenadoria Nacional Para Integração da Pessoa Portadora de Deficiência - CORDE. [Internet]. [citado 2017 Jan 13]. Disponível em: http://www.mj.gov.br/sedh/ct/corde/dpdh/corde/normas_abnt.asp.

3. Pereira CM, Alves MA participação do enfermeiro na implantação do Programa Saúde da Família em Belo Horizonte. Rev Bras Enferm. 2015;57(3):311-5.

4. Aragão $A E$, Pagliuca LM, Almeida $P C$, Macedo KN. Instalações sanitárias, equipamentos e áreas de circulação em hospitais: adequações aos deficientes. Rev RENE. 2009;9(1):36-44. 
5. Vasconcelos LR, Pagliuca LM. Mapeamento da acessibilidade do portador de limitação física a Serviços Básicos de Saúde. Esc Anna Nery. 2009;10(3):494-500.

6. Jorge MH, Laurenti R, Gotlieb SL. Avaliação dos sistemas de informação em saúde no Brasil. Cad Saúde Coletiva. 2017;18(1):7-18.

7. Pagliuca LM, Uchoa RS, Machado MM. Pais cegos: experiências sobre 0 cuidado dos seus filhos. Rev Lat Am Enferm. 2009;17(2):137-9.

8. Jorge HM, Bezerra JF, Oriá MO, Brasil CC, Araujo ML, Silva RM. Enfrentamento de mães cegas no acompanhamento dos filhos menores de 12 anos. Texto Contexto Enferm. 2014;23(4):1013-21.

9. Minayo MC. 0 desafio do conhecimento: pesquisa qualitativa em saúde. 14a ed. São Paulo: Hucitec; 2015.

10. Haguette TM. Metodologias qualitativas na sociologia. 4a ed. Petrópolis: Vozes; 2013.

11. Bardin L. Análise de conteúdo. Lisboa: Edições 70; 2016.

12. Santos IS, Baroni RC, Minotto I, Klumb AG. Critérios de escolha de postos de saúde para acompanhamento pré-natal em Pelotas, RS. Rev Saúde Pública. 2017;34(6):603-9.

13. Seque CA, Kawazoe L, Silva EM, Puccini RF. Assistência pré-natal e ao parto de mães de crianças usuárias do serviço de vacinação de unidade de saúde da cidade de São Paulo. Rev Paul Pediatr. 2015; 25(1):38-46.

14. Silveira DS, Santos IS, Costa JS. Atenção pré-natal na rede básica: uma avaliação da estrutura e do processo. Cad Saúde Pública. 2016;17(1):131-9.
15. Machado MM, Leitão GC, Holanda FU. 0 conceito de ação comunicativa: uma contribuição para a consulta de enfermagem. Rev Lat Am Enferm. 2010;13(5):723-8.

16. Giugliani ER. Problemas comuns na lactação e seu manejo. J Pediatr. 2014; 80(Supl 5):147-54.

17. Teixeira NZ, Pereira WR. Parto hospitalar - experiências de mulheres da periferia de Cuiabá-MT. Rev Bras Enferm. 2016;59(6):740-4.

18. Rattner D. Humanizing childbirth care: brief theoretical framework. Interface Comunic Saúde Educ. 2016;13(Suppl 1):595-602.

19. Rabelo LR; Oliveira DL. Percepções de enfermeiras obstétricas sobre sua competência na atenção ao parto normal hospitalar. Rev Esc Enferm USP. 2016;44(1):213-20.

20. Tornquist CS. Paradoxos da humanização em uma maternidade no Brasil. Cad Saúde Pública. 2013;19(Supl 2):419-27.

21. Brasil. Ministério da Saúde. Secretaria de Atenção à Saúde. Núcleo Técnico da Política Nacional de Humanização. Humaniza SUS: visita aberta e direito a acompanhante. 2a ed. Brasília (DF): Ministério da Saúde; 2015.

22. Brasil. Ministério da Saúde. Secretaria de Atenção à Saúde. Departamento de Ações Programáticas Estratégicas. Manual de legislação em saúde da pessoa com deficiência. 2a ed rev atual. Brasília (DF): Ministério da Saúde; 2010.

23. Blank D. A puericultura hoje: um enfoque apoiado em evidências. J Pediatr. 2017; 79(Supl 1):13-22.

24. Cezário KG, Pagliuca LM. Tecnologia assistiva em saúde para cegos: enfoque na prevenção de drogas. Esc Anna Nery. 2007;11(4): 677-81. 